\title{
A (RE)CONSTRUÇÃO DA IDENTIDADE DO PROFESSOR DE LÍNGUA INGLESA SOB A ÓTICA DE PESQUISADORES PARANAENSES
}

\author{
Didiê Ana Ceni DENARDI \\ Ederson Henrique de SOUZA MACHADO \\ Camila Paula CAMILOTTI \\ Universidade Tecnológica Federal do Paraná
}

\begin{abstract}
RESUMO: Conhecer como se dá a (re)construção da identidade profissional docente é crucial para o aprimoramento de cursos de formação inicial e continuada de professores de línguas adicionais, neste caso de língua inglesa. Baseando-se nesse pressuposto, este artigo visa apresentar resultados preliminares do projeto de pesquisa "(Re)construção da identidade do professor de língua inglesa sob a ótica de pesquisadores paranaenses", cujo objetivo é o de investigar o conceito de identidade e conceitos adjacentes discutidos nos estudos referentes à formação de professores de Língua Inglesa desenvolvidos por pesquisadores de Programas de Pós-Graduação de instituições de ensino do Paraná no período de 2007 a 2016, bem como fazer um levantamento das características presentes nos estudos selecionados. Os dados foram coletados através de busca de trabalhos sobre a temática nos curriculum lattes de professores de programas de pós-graduação em Letras/Linguística de universidades estaduais e federais do Paraná, reconhecidos pela CAPES, verificando-se na seção "publicações em periódicos", artigos cujo título continha a palavra "identidade" e que esses estivessem relacionados à formação de professores de inglês. Cinco artigos foram identificados e tomados para uma análise descritiva. Os estudos foram analisados utilizando-se dos tópicos: a) contexto de produção; b)objetivo; c) definição do conceito de identidade profissional docente; d) metodologia de pesquisa e e) resultados e conclusões dos pesquisadores Em geral, os estudos apontam para o conceito da identidade profissional do professor de inglês como um processo reflexivo que está em constante transformação devido às mudanças na sociedade contemporânea e que se constitui na interação com o outro através das experiências no trabalho e em outros contextos sociais.
\end{abstract}

PALAVRAS-CHAVE: (Re)construção da identidade profissional; Professor de inglês; Contexto paranaense.

ABSTRACT: Understanding how the (re)construct the professional identity of teachers is crucial for the development of initial and continuing teacher education in additional languages, in this case, the English language. Within this perspective, the present article aims at showing some preliminary results from the research project entitled "(Re)construção da identidade do professor de língua inglesa sob a ótica de pesquisadores paranaenses", which has the intent of investigating the concept of identity and adjacent concepts discussed in studies related to teacher education in English language developed by researchers from Graduate programs of Educational institutions located in the state of Parana from 2007 to 2016. The research project also aims at making a survey on the characteristics found in correlated studies. The data were collected through search of academic papers and works on the subject matter located in the curriculum lattes of professors of undergraduate and graduate programs in the field of Language/Linguistics from public universities of Paraná state, acknowledged by CAPES. In this survey procedure, articles or papers related to the themes identity and teacher education were searched in the "scientific journal publications" section of the professors' curriculum lattes. Five papers were identified and submitted to a descriptive analysis. The studies were analyzed within the following topics: context of 
production, objective, definition of the concept of professional teacher identity, research methodology, results and conclusions of the researchers. In general, the studies indicate the concept of professional identity of English teachers as a reflexive process which is in constant transformation due to the changes in the contemporary society and it is constituted within the interaction with the other through experiences in the work environment and in other social contexts.

KEYWORDS: (Re)construction of professional identity; English teacher; Paraná context.

\section{Introdução}

Considerando a importância de conhecer a identidade profissional docente do professor de língua inglesa e suas implicações no processo de ensino-aprendizagem de línguas de forma a aprimorar a prática de professores em formação inicial e continuada dessa área, este artigo tem como objetivo geral apresentar dados parciais do projeto de pesquisa "A (re)construção da identidade do professor de língua inglesa sob a ótica de pesquisadores paranaenses". Especificamente, o artigo visa investigar o conceito de identidade e conceitos adjacentes discutidos nos estudos referentes à formação de professores de Língua Inglesa desenvolvidos por pesquisadores de Programas de Pós-Graduação de instituições de ensino superior do Paraná no período de 2007 a 2016, bem como fazer um levantamento das características presentes nos estudos selecionados.

Pode-se dizer que, de certa forma, o presente artigo dá continuidade aos estudos já desenvolvidos por Camargo-Quevedo e Ramos (2007) e El Kadri (2010). Os estudos de Quevedo-Camargo procuraram fazer um levantamento de pesquisas sobre a identidade de professores de inglês no contexto brasileiro por meio de dissertações e teses publicadas de 2000 a 2006, enquanto que os de El Kadri atualizam tais dados ao revisar pesquisas sobre a temática publicadas em artigos e dissertações no período de 2006 a outubro de 2008, também a nível nacional. $\mathrm{O}$ estudo que ora se apresenta, por sua vez, procura dar continuidade aos estudos anteriores, porém limitando-se ao contexto paranaense, uma vez que é parte de um projeto de pesquisa maior, intitulado " $(\mathrm{Re})$ construção da identidade do professor de língua inglesa sob a ótica de pesquisadores paranaenses". O referido projeto pretende investigar trabalhos publicados em anais de eventos científicos, periódicos, capítulo de livros e banco de teses e dissertações de programas de pós-graduação do contexto paranaense no período de 2006 a 2016. Este artigo, por sua vez, apresenta apenas um levantamento de pesquisas publicadas em periódicos científicos indexados no período de tempo já mencionado.

O presente artigo está organizado em quatro seções, além desta breve introdução. A primeira seção procura discutir a importância da linguagem no desenvolvimento e na (re)construção da identidade docente. Já a segunda, descreve a seleção de dados e demais aspectos metodológicos da pesquisa. Por sua vez, a terceira busca sistematizar e mapear os trabalhos de pesquisa desenvolvidos no contexto universitário paranaense entre 2006 a 2016, bem como apresentar resultados da sistematização desenvolvida. Por fim, a quarta seção apresenta algumas considerações sobre o percurso traçado.

\section{Linguagem, desenvolvimento e identidade profissional docente}

Entender a linguagem verbal como dialógica e sócio-histórica (BRONCKART, 2003, 2006, 2008), uma vez que se constitui e é constituída de atividades e comportamentos humanos, e é significativa para a formação da mente e construção do conhecimento, é concebê-la como fundamental ao desenvolvimento humano, e portanto, ao desenvolvimento do professor e de sua identidade docente. 
Nesse sentido, o desenvolvimento humano, a construção de conhecimento e a construção de conhecimento de si (construção de identidade) emergem das interações sociais entre os indivíduos mediados pela linguagem (ou linguagens), uma vez que essa possibilita que funções superiores, tais como 'a atenção', 'a percepção,', 'a memória', 'a avaliação', 'o raciocínio lógico' e, também, 'a própria linguagem verbal' aflorem e se desenvolvam (VYGOTSKY, 1978 ), formando subjetividades num processo contínuo e espiralado de amadurecimento que se desenvolve ininterruptamente ao longo de toda a vida dos sujeitos.

Tal processo, não linear, é explicado por Vygotsky (1978) por meio do conceito metafórico de zona de desenvolvimento proximal (ZDP) que é entendido como um estágio intermediário entre o conhecimento que o indivíduo já tem (zona de conhecimento real) e o conhecimento que ele pode vir a ter (zona de conhecimento potencial). Entre os 2 estágios mencionados, há um estágio de cognição (amadurecimento) que permite o desenvolvimento de conhecimentos novos (zona de desenvolvimento proximal), em determinadas situações desde que mediados por pares mais experientes. Ademais, quando o indivíduo adquire esse novo conhecimento, já se encontra novamente em condições de ou no estágio de adquirir outros novos conhecimentos, em um processo continuo.

$\mathrm{Na}$ formação docente - inicial ou continuada - é, obviamente, a linguagem que possibilita que a comunicação se efetive e o conhecimento científico ${ }^{1}$ seja construído como um todo sobre questões relativas ao processo de ensino-aprendizagem, seja via trocas e interlocuções de professores e alunos mestres, seja via de leituras variadas, de textos estudados, de experiências e práticas pedagógicas vivenciadas, permitindo que o desenvolvimento do professor, bem como a construção do sentido de saber ser professor, isto é a (re)construção da identidade profissional docente, floresçam e se consolidem. Nesse sentido, desenvolvimento e identidade profissional encontram-se intrinsicamente relacionados e se constituem pela linguagem.

Por desenvolvimento profissional docente, entende-se o conjunto de saberes necessários para o professor desenvolver seu trabalho (ELBAZ, 1981, SHULMAN, 1987, TELLES, 1997, RICHARDS, 1998, NOVOA, 2002, PLACCO, 2006). Já por identidade profissional docente pode-se entender as representações que o docente tem de si mesmo, (ROSSI, 2008), bem como o entendimento das representações que outros tem do docente, uma vez que "conhecemo-nos a nós mesmos porque conhecemos os outros, pois somos, em relação a nós mesmos, os mesmos que os outros em relação a nós" (VYGOTSKY, 19251994, p. 47).

Ademais, segundo Scoz (2001),

Considerando os sentidos que os professores produzem em seus processos de aprender e de ensinar, também podemos ter acesso à maneira como eles se situam como sujeitos pensantes, bem como às emoções produzidas em diversas situações de ensino e aprendizagem em diferentes momentos e espaços de suas vidas (p. 49).

Acredita-se que o inverso do pensamento acima é também possível ao considerar que a maneira como os professores se situam como sujeitos pensantes pode revelar e influenciar suas atuações e comportamentos no processo de ensinar e aprender, especialmente os professores de línguas. Segundo Rajagopalan (2003), "as línguas são a própria expressão das identidades de quem delas se apropria. Logo quem transita entre diversos idiomas está redefinindo sua própria identidade" (p.69). Dessa forma, conclui-se sobre a importância da pesquisa sobre construção de identidade do professor, em nosso caso o de inglês, e ao mesmo tempo, a importância de envolver professores em formação inicial e continuada em reflexões sobre o que é ser professor de línguas no mundo contemporâneo, sobre suas práticas

\footnotetext{
${ }^{1}$ Vygotsky (1978) distingue conhecimento espontâneo de conhecimento científico, sendo o primeiro entendido como aquele que emergem naturalmente nas interações e o segundo como aquele cuja construção precisa ser sistematizada e mediada por pares mais experientes.
} 
pedagógicas, sobre o papel da língua inglesa no mundo, sobre aspectos interculturais, interdisciplinares presentes nos textos orais e escritos aos quais os professores têm acesso de modo a contribuir para a melhoria da qualidade da formação de professores de inglês no contexto brasileiro.

\section{Aspectos metodológicos}

Retomando o objetivo geral deste texto que é o de investigar o conceito de identidade e conceitos adjacentes discutidos nos estudos referentes à formação docente de Língua Inglesa desenvolvidos por pesquisadores de Programas de Pós-Graduação de instituições de ensino superior do Paraná no período de 2007 a 2016, bem como fazer um levantamento das características presentes nos estudos selecionados, será relatado nesta seção como se deu a seleção e análise dos textos publicados em periódicos da área.

\section{Seleção de textos}

A geração da amostra foi realizada via internet e teve os seguintes procedimentos e respectivos resultados: a) verificação de programas de pós-graduação em Letras/Linguísticas, reconhecidos pela CAPES e existentes no Paraná. Neste quesito foram identificados 7 programas, alocados nas universidades: Universidade Estadual do Centro Sul - Unicentro de Guarapuava, Universidade Estadual do Oeste- Unioeste, de Cascavel, Universidade Estadual de Londrina- UEL em Londrina, Universidade Estadual de Maringá- UEM em Maringá, Universidade Federal do Paraná - UFPR em Curitiba e Universidade Tecnológica Federal do Paraná - UTFPR - nos Campi Curitiba e Pato Branco; b) verificação, nos sítios dos programas de pós-graduação, de docentes que atuam na área de formação de professores, com possíveis produções sobre a temática pesquisada. Aquil9 pesquisadores foram identificados; e c) busca de, no currículo lattes dos professores identificados, títulos de artigos relacionados à temática pesquisada publicados em periódicos no período de 2006 a 2016. Foram encontrados 21 artigos da área de formação de professor de língua inglesa, com temas correlatos ao da pesquisa. A partir desses 21, escolheu-se aqueles cujo título continha a palavra "identidade". Dessa forma, apenas 5 artigos foram encontrados e serão aqui analisados.

\section{Análise dos textos}

Uma análise interpretativista do corpus procurou identificar nos 5 artigos os seguintes tópicos: contextos de produção (título, temática, objetivos, autoria, local e data de publicação); os referenciais teóricos usados; conceito de identidade, metodologias adotadas e principais resultados e/ou conclusões dos trabalhos produzidos no contexto paranaense. Buscou-se, também, responder a duas perguntas de pesquisas: a) Como os estudos de pesquisadores paranaenses são caracterizados?; e b) Como a identidade profissional é conceituada nas pesquisas investigadas?

\section{MAPEAMENTO DAS PESQUISAS}

\section{Apresentação e sistematização das pesquisas}

Nesta subseção, apresenta-se e sistematiza-se os 5 trabalhos selecionados, isto é aqueles em cujo título há a palavra "identidade". Primeiramente, apresentamos as pesquisas com relação aos títulos e temáticas, autorias e contextos de produção/publicação por ordem cronológica, no Quadro1, abaixo. 


\begin{tabular}{|c|c|c|c|}
\hline Número & Título & Autor (es)/Contexto de Produção & Meio de Publicação \\
\hline 1 & $\begin{array}{l}\text { Narratives: unveiling } \\
\text { teachers' identities }\end{array}$ & $\begin{array}{l}\text { Marimar da Silva, Saionara } \\
\text { Greggio, Camila Lucena, Didiê } \\
\text { Ana Ceni Denardi, Gloria Gil } \\
\text { Universidade Tecnológica } \\
\text { Federal do Paraná / Universidade } \\
\text { Federal de Santa Catarina / } \\
\text { Universidade Federal de Santa } \\
\text { Catarina }\end{array}$ & $\begin{array}{l}\text { Signum. Estudos de } \\
\text { Linguagem, v. 10, p. } \\
\text { 199-222, 2007. } \\
\text { Universidade Estadual } \\
\text { de Londrina/PR }\end{array}$ \\
\hline 2 & $\begin{array}{l}\text { A posição de professor de } \\
\text { inglês no Brasil; } \\
\text { hibridismo, identidade e } \\
\text { agência }\end{array}$ & $\begin{array}{l}\text { Clarissa Jordão } \\
\text { Universidade Federal do Paraná }\end{array}$ & $\begin{array}{l}\text { Letras \& Letras. v. 26, } \\
\text { p. } 427-442,2010 . \\
\text { Universidade Federal de } \\
\text { Uberlância/ MG }\end{array}$ \\
\hline 3 & $\begin{array}{l}\text { A construção de identidade } \\
\text { profissional no Estágio de } \\
\text { Regência de Inglês }\end{array}$ & $\begin{array}{l}\text { Raquel Gamero, Vera } \\
\text { Lopes Cristovão } \\
\text { Universidade } \\
\text { Londrina/PR }\end{array}$ & $\begin{array}{l}\text { Revista Eletrônica do } \\
\text { Pro- Docência, v. 1, p. } \\
\text { 80-92, 2013. } \\
\text { Universidade Estadual } \\
\text { de Londrina/PR }\end{array}$ \\
\hline 4 & $\begin{array}{l}\text { Uma análise linguístico- } \\
\text { discursiva das marcas } \\
\text { identitárias do professor de } \\
\text { língua inglesa }\end{array}$ & $\begin{array}{l}\text { Didiê Ana Ceni Denardi, } \\
\text { Siderlene Muniz Oliveira } \\
\text { Universidade Tecnológica } \\
\text { Federal do Paraná }\end{array}$ & $\begin{array}{l}\text { Eutomia (Recife), v. } 1 \text {, } \\
\text { p. 562-580, 2014. } \\
\text { Universidade Federal de } \\
\text { Pernambuco }\end{array}$ \\
\hline 5 & $\begin{array}{l}\text { How do I see myself? } \\
\text { What do I want to } \\
\text { become? A study on } \\
\text { English as an additional } \\
\text { language teachers' identity } \\
\text { reconstruction }\end{array}$ & $\begin{array}{l}\text { Didiê Ana Ceni Denardi, Gloria } \\
\text { Gil } \\
\text { Universidade Tecnológica } \\
\text { Federal do Paraná / Universidade } \\
\text { Federal de Santa Catarina }\end{array}$ & $\begin{array}{l}\text { Trabalhos em } \\
\text { Linguística Aplicada, v. } \\
\text { 54, p. 137-160, 2015. } \\
\text { Universidade Estadual } \\
\text { de Campinas/SP }\end{array}$ \\
\hline
\end{tabular}

Quadro 1: Títulos, contextos de produção e meio de publicação dos artigos

Com relação aos contextos de produção dos artigos 1,2,4 e 5, apresentados no quadro acima, observa-se nos currículos lattes dos pesquisadores que os mesmos não foram publicados em periódicos das universidades nas quais seus autores trabalham como professores e pesquisadores de programas de pós-graduação. Esses foram submetidos a revistas científicas de universidades distantes das de origem do contexto de produção e dessa forma alcançando novos leitores. Exceção do estudo número 3, de Gamero e Cristovão (2013) que foi publicado em revista eletrônica da instituição das autoras.

A seguir, uma síntese dos trabalhos será apresentada no Quadro 2, contemplando a identificação do estudo, os objetivos, os aportes teóricos que os embasam e conceito de identidade, metodologia e resultados.

\begin{tabular}{|c|c|c|c|c|c|}
\hline $\mathrm{N}^{\circ}$ & Identificação & Objetivo(s) & $\begin{array}{ll}\text { Aporte(s) } & \\
\text { Teórico(s) } & \text { e } \\
\text { Conceito } & \text { de } \\
\text { Identidade } & \end{array}$ & Metodologia & Resultados \\
\hline 1 & $\begin{array}{l}\text { Da Silva et al. } \\
(2007)\end{array}$ & $\begin{array}{l}\text { Identificar o } \\
\text { conhecimento } \\
\text { prático de } \\
\text { professores de } \\
\text { inglês em } \\
\text { formação } \\
\text { continuada a nível } \\
\text { de pós-graduação, } \\
\text { observando suas } \\
\text { regras, princípios }\end{array}$ & $\begin{array}{l}\text { Freeman; Johnson } \\
\text { (1998, 2001), } \\
\text { Freeman;Richards } \\
\text { (1996), } \\
\text { Richards; Nunan } \\
\text { (1990), } \\
\text { Elbaz (1981), } \\
\text { Clandinin; } \\
\text { Connelli (1987), } \\
\text { Telles (1997; }\end{array}$ & $\begin{array}{l}\text { Coleta: } \\
\text { Produção escrita } \\
\text { de narrativas de } \\
\text { vida de } 4 \\
\text { professores ; } \\
\text { Gravações das } \\
\text { narrativas em } \\
\text { áudio e } \\
\text { transcrições }\end{array}$ & $\begin{array}{l}\text { Conjunto de } \\
\text { histórias } \\
\text { biográficas } \\
\text { que } \\
\text { permitiram } \\
\text { aos } \\
\text { participantes } \\
\text { construir } \\
\text { conecções } \\
\text { significativas }\end{array}$ \\
\hline
\end{tabular}




\begin{tabular}{|c|c|c|c|c|c|}
\hline & & $\begin{array}{l}\text { e práticas através } \\
\text { de suas narrativas } \\
\text { de vida. }\end{array}$ & $\begin{array}{l}\text { 2002;2004) } \\
\text { Identidade: } \\
\text { conhecimento } \\
\text { prático do } \\
\text { professor }\end{array}$ & $\begin{array}{l}\text { Categorias de } \\
\text { análise: } \\
\text { identificação do } \\
\text { tipo de narrativa; } \\
\text { do conhecimento } \\
\text { prático dos } \\
\text { participantes; e } \\
\text { mapeamento das } \\
\text { metáforas } \\
\text { construídas } \\
\text { pelos } \\
\text { professores }\end{array}$ & $\begin{array}{l}\text { entre } \\
\text { diferentes } \\
\text { momentos de } \\
\text { suas vidas e a } \\
\text { construção de } \\
\text { seus } \\
\text { conhecimen } \\
\text { tos práticos e } \\
\text { redescobertas } \\
\text { de si }\end{array}$ \\
\hline 2 & Jordão (2010) & $\begin{array}{lr}\text { Refletir } & \text { sobre } \\
\text { questões } & \text { de } \\
\text { ensino- } & \\
\text { aprendizagem de } \\
\text { Inglês como } \\
\text { língua } \\
\text { internacional }\end{array}$ & 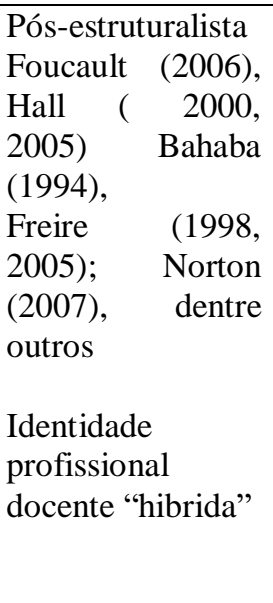 & $\begin{array}{l}\text { Pesquisa } \\
\text { bibliográfica } \\
\text { baseada em } \\
\text { textos de } \\
\text { pesquisadores } \\
\text { pós- } \\
\text { estruturalistas } \\
\text { sobre a temática }\end{array}$ & $\begin{array}{l}\text { Professores } \\
\text { têm } \\
\text { "identidade } \\
\text { hibrída", que } \\
\text { se engaja com } \\
\text { a língua e a } \\
\text { cultura } \\
\text { estrangeira e, } \\
\text { consequentem } \\
\text { ente, } \\
\text { acrescenta sua } \\
\text { língua } \\
\text { cultura nativa } \\
\text { num processo } \\
\text { reflexivo }\end{array}$ \\
\hline 3 & $\begin{array}{l}\text { Gamero; } \\
\text { Cristovão } \\
(2013)\end{array}$ & $\begin{array}{lr}\text { Investigar } & \text { a } \\
\text { construção } & \text { da } \\
\text { identidade } & \text { de } \\
\text { futuros } & \\
\text { professores } & \text { de } \\
\text { inglês de uma } \\
\text { turma de } 4^{\text {o ano }} \\
\text { de graduação de } \\
\text { uma universidade } \\
\text { pública do norte } \\
\text { do Paraná em } \\
\text { estágio curricular } \\
\text { através } \\
\text { programa parceria } \\
\text { universidade- } \\
\text { escola }\end{array}$ & $\begin{array}{l}\text { Interacionismo } \\
\text { Socio Discursivo } \\
\text { (ISD) machado } \\
(1998), \text { Bronckart } \\
(1999), \quad \text { Rossi } \\
(2004), \text { Gimenez } \\
(2002), \text { Liberalli } \\
(1999), \text { Furtoso et } \\
\text { al (2009) }\end{array}$ & $\begin{array}{l}\text { Coleta: diários } \\
\text { de } 3 \text { alunas } \\
\text { produzidos } \\
\text { durante o } \\
\text { Estágio } \\
\text { Curricular } \\
\text { Análise: de } \\
\text { ordem } \\
\text { semântica, } \\
\text { levantamen } \\
\text { to temático e de } \\
\text { contexto de } \\
\text { produção }\end{array}$ & $\begin{array}{l}\text { indícios de } \\
\text { formação } \\
\text { reflexiva } \\
\text { A identidade } \\
\text { profissional é } \\
\text { um processo } \\
\text { de construção }\end{array}$ \\
\hline 4 & $\begin{array}{l}\text { Denardi; } \\
\text { Oliveira (2014) }\end{array}$ & $\begin{array}{l}\text { Investigar a } \\
\text { (re)construção de } \\
\text { da identidade de } 6 \\
\text { professoras de } \\
\text { rede pública } \\
\text { estadual de ensino } \\
\text { do sudoeste do } \\
\text { Paraná através de } \\
\text { programa parceria } \\
\text { universidade - } \\
\text { escola }\end{array}$ & $\begin{array}{l}\text { Interacionismo } \\
\text { Sociointeraciodis } \\
\text { cursivo - ISD, } \\
\text { Bronckart } \\
(1999), \\
\text { Identidade } \\
\text { entendida como } \\
\text { mutável, em } \\
\text { constante as } \\
\text { (re)construção } \\
\text { devido } \\
\text { transformações } \\
\text { sócio-históricas }\end{array}$ & $\begin{array}{lr}\text { Coleta: textos } \\
\text { audiogravados } \\
\text { transcritos, } \\
\text { narrativas } \\
\text { vida de de } \\
\text { professoras } \\
\text { comentário } \\
\text { escrito sobre a } \\
\text { identidade } \\
\text { profissional } \\
\text { docente } \\
\text { Análise } \\
\text { conteúdo de } \\
\text { temático (BRON } \\
\text { CKART, 1999), } \\
\text { figuras de ação e } \\
\text { vozes }\end{array}$ & $\begin{array}{l}\text { os textos } \\
\text { revelam } \\
\text { aspectos da } \\
\text { identidade dos } \\
\text { professores, } \\
\text { tais como o } \\
\text { esforço } \\
\text { individual e o } \\
\text { senso de } \\
\text { responsabili } \\
\text { dade sobre a } \\
\text { aprendiza } \\
\text { gem dos } \\
\text { alunos }\end{array}$ \\
\hline
\end{tabular}




\begin{tabular}{|c|c|c|c|c|c|}
\hline 5 & $\begin{array}{l}\text { Denardi; } \quad \text { Gil } \\
(2015)\end{array}$ & $\begin{array}{l}\text { Investigar a } \\
\text { (re)construção de } \\
\text { da identidade de } 6 \\
\text { professoras de } \\
\text { rede pública } \\
\text { estadual de ensino } \\
\text { do sudoeste do } \\
\text { Paraná através de } \\
\text { programa } \\
\text { parceria- } \\
\text { universidade } \\
\text { escola }\end{array}$ & 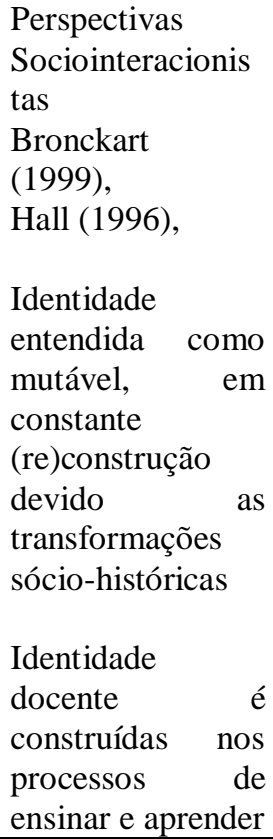 & $\begin{array}{l}\text { Textos orais } \\
\text { gravados e } \\
\text { transcritos sobre } \\
\text { ensino- } \\
\text { aprendizagem, } \\
\text { Narrativas de } \\
\text { vida, } \\
\text { Comentário } \\
\text { escrito sobre si } \\
\text { Análise: } \\
\text { Qualitativa- } \\
\text { interpretati } \\
\text { vista }\end{array}$ & $\begin{array}{l}\text { identidades } \\
\text { fragmenta } \\
\text { das e } \\
\text { relacionadas } \\
\text { ao processo de } \\
\text { vida dos } \\
\text { professores, } \\
\text { professores } \\
\text { em constante } \\
\text { mudança e } \\
\text { desenvolvime } \\
\text { nto } \\
\text { profissional, } \\
\text { as trajetórias } \\
\text { de vida dos } \\
\text { professores } \\
\text { são essenciais } \\
\text { na construção } \\
\text { de suas } \\
\text { identidades }\end{array}$ \\
\hline
\end{tabular}

Quadro 2: Tematização, conceito de identidade, metodologia e resultados das pesquisas investigadas

O trabalho de Da Silva et al. (2007) refere-se a uma pesquisa qualitativainterpretativista que buscou identificar o conhecimento prático de 4 professoras de inglês em formação continuada a nível de doutorado. Segundo Elbaz (1981), o conhecimento prático do professor é entendido como aquele construído através das experiências do professor na interação com pares e alunos e se constitui de regras, princípios e práticas que determinam seu fazer docente. $\mathrm{O}$ acesso ao conhecimento prático das participantes ocorreu através de suas narrativas de vida. Cada participante produziu oralmente, audiogravou e transcreveu sua narrativa, na sequência as narrativas foram trocadas para serem analisadas à luz das categorias "regras", "princípios" e "práticas". Na análise também foram identificadas e mapeadas as metáforas produzidas pelas participantes. Segundo as autoras, a pesquisa ofereceu uma oportunidade para reflexão e/ou reconstrução de suas identidades profissionais docentes, uma vez que aspectos desconhecidos de suas identidades, de certa forma, se tornaram mais evidentes. Ademais, as narrativas de vida podem contribuir para o acesso ao conhecimento prático do professor, o que pode significar uma alternativa para possíveis mudanças de níveis intelectual e comportamental se utilizadas como instrumento para reflexão nos primeiros estágios da profissão docente.

Tendo como objetivo discutir a (des)construção da identidade do professor de inglês no Brasil "a partir de um referencial teórico pós-estruturalista usado para refletir sobre questões de ensino-aprendizagem de inglês como língua internacional" (p.427), Jordão (2010) aborda 2 principais questões. A primeira refere-se à relação educação e o papel do inglês na sociedade brasileira contemporânea, apontando para a influência da cultura e de visões de mundo que países de primeiro mundo exercem na formação de professores de inglês no Brasil. Tal influência pode ser evidenciada por vários aspectos, dentre os quais destaca-se: a) a insistência na distinção entre nativo e não nativo com relação ao ensino-aprendizagem da língua, fazendo com que professores não nativos se percebam em posições subalternas em relação aos nativos, uma vez que esses teriam autoridade sobre sua própria língua; b) a língua inglesa entendida como comodity; c) o conceito de letramento entendido como habilidade intelectual e em decorrência disso, as pessoas que sabem inglês seriam mais "hábeis intelectualmente' que outras; e d) a formação de professores no Brasil tem seguido modelos de ensino-aprendizagem internacionais que geralmente não atendem às necessidades do contexto brasileiro. Professores e estudantes, por sua vez, oferecem resistência a esses 
modelos impostos, muitas vezes fracassados, acabando em frustrações e na crença de que não se aprende inglês na escola pública. Em suma, sobre essa questão, a autora afirma que a atividade educacional é uma atividade política que envolve questões sociais, culturais, econômicas e identitárias.

Partindo da perspectiva de que a educação é uma atividade política, Jordão aborda sua segunda questão: as concepções de hibridismo e agência no contexto de ensino-aprendizagem de inglês no Brasil. Ela inicia ponderando a necessidade de se entender as noções de diferença, agência e resistência. De forma geral a diferença é "um processo de representações simbólicas construído discursivamente (...) sobre o que constitui a identidade e o que constitui a diferença" (p.431) no sujeito. Assim, o sujeito que constrói e é construído por essa narrativa é um sujeito discursivo e portanto, "tanto sujeito como discurso são fragmentados, contingentes, localizados apenas provisoriamente" (p.431). Seguindo esse raciocínio, a autora pondera que "o sujeito pode oferecer resistência e agir sobre a diferença em seu processo de construção" quando da percepção de representações conflitantes. Neste quadro, a agência não é apenas uma ação específica, mas sim "uma forma de intervir no processo discursivo de construção de sentidos e representações do mundo" (p.432).

Especificamente com relação ao ensino-aprendizagem de inglês no Brasil, a autora discute as razões do fracasso do ensino e da aprendizagem de inglês nas escolas públicas que vão desde condições precárias de infraestrutura, má formação dos professores e desinteresse dos estudantes. No entanto, pondera a possibilidade de uma transformação nesse quadro desolador desde que se a educação (professores e estudantes) se posicione "ao lado do uso opressor do poder, relações de poder na sociedade (...) que produzem conhecimento (...) no estabelecimento e modificações de certas relações" (p.435). Dessa forma, a escola poderia "almejar que sujeitos críticos (...) pudessem agir discursivamente sobre os discursos que os constituem", ou seja que os sujeitos fossem capazes de posicionarem-se criticamente ao conscientizarem-se de que certas formas de saber também sejam respeitadas, bem como aqueles que as exercitam.

Depreende-se, portanto, do estudo de Jordão (2010) que alunos e professores são vistos como sujeitos "híbridos (...) aptos a operar nas fissuras dos discursos autoritários (BAKHTIN, 1981), sendo capazes de transformar -contingencialmente - esses mesmos discursos" (p. 439).

Gamero e Cristovão (2013) desenvolvem o estudo tendo como participantes 3 alunasprofessoras em estágio de docência, fugindo ao modelo tradicional, uma vez que a cada aula ministrada, as alunas registraram em seus diários suas experiências, reflexões e questionamentos sobre o trabalho docente. Dessa forma, o diário é tomado como instrumento de reflexão sobre a prática pedagógica, bem como um mecanismo em potencial para a (re) construção da identidade profissional docente. Segundo as autoras, o diário pode "desencadear um processo de transformação e emancipação em situações escolares ou de formação de educadores (p.84).

Nos diários, as três alunas-professoras escreveram sobre os seguintes conteúdos temáticos: a) contextualização; b) frustração na prática; c) ensino de inglês no colégio que foi realizado o estágio; d) fatores que agem na prática (participação do aluno, dificuldades de aprendizagem dos alunos, planejamento e gerenciamento, motivação, influência externa e autoridade); e) planos e estratégias para o crescimento; f) interferências da ação e do discurso do outro; e g) atitude reflexiva sobre a própria prática. Segundo as autoras, por meio da visualização dos temas foi possível ter acesso às "representações desenvolvidas ou reforçadas" das alunas-professoras sobre a docência e que influenciaram a construção de suas identidades profissionais, bem como perceber que à medida que as mesmas se frustram, avaliam e reveem suas posturas e comportamentos como profissionais. As autoras também manifestam a ausência de pressupostos teóricos embasando as reflexões das participantes, apesar de haver uso frequente de aportes teóricos sobre atitude reflexiva sobre a prática pedagógica na disciplina de prática de ensino de inglês. Como uma possível resposta a essa 
questão, as autoras afirmam que asalunas vem construindo suas identidades profissionais ao longo de suas histórias e não apenas no momento do estágio. Corrobora-se da afirmação das autoras de que a identidade é construída sócio-historicamente, e dessa forma as influências que as alunas-professoras receberam ao longo de suas vidas como estudantes, mesmo no curso de licenciatura, foram mais fortes que as recebidas no período de estágio e enquanto participantes da disciplina de prática de ensino. Constata-se aqui, também, a dificuldade do professor em relacionar teoria e prática e dessa forma reconfigurar sua prática e a si mesmo, o que muitos pesquisadores e formadores de professores de linguística aplicada ao ensino de línguas (GIMENEZ, 1999, 2002, CELANI; MAGALHÃES, 2002, NÓVOA, 2002, ZEICHNER,2003, ORTENZI et al, 2008, dentre outros) vêm discutindo e é uma das razões do movimento reflexivo existir.

Os trabalhos de Gamero e Cristovão (2013), de Denardi e Oliveira (2014) e de Denardi e Gil (2015) têm como objetivo investigar a construção da identidade profissional de professores em contextos de programas de extensão parceria universidade-escola. Enquanto o primeiro investiga a identidade de professores em formação de uma universidade pública do norte do Paraná, os seguintes investigam a identidade de professores em serviço em escolas públicas no sudoeste do Estado.

Os estudos de Denardi e Oliveira (2014) e Denardi e Gil, 2015 serão aqui revisados conjuntamente, uma vez que têm os mesmos objetivos e são oriundos de um mesmo contexto de pesquisa, ou seja, ambos os estudos se valem dos mesmos dados e informações coletadas no curso de extensão "Escrita e identidade do professor de Inglês", ocorrido em 3 oficinas durante o ano de 2013 integradas ao Programa de Extensão Universitária denominado "Integração e Formação em Letras Português e Inglês" do Curso de Licenciatura em LetrasPortuguês e Inglês da Universidade Tecnológica Federal do Paraná (UTFPR), Pato Branco, Estado do Paraná. Participaram do curso 38 professores de inglês de escolas estaduais da região sudoeste do Paraná e a professora pesquisadora, no entanto apenas 6 professoras frequentaram integralmente as 3 oficinas e, portanto, são essas as participantes focais dos estudos. Nas oficinas as professoras produziram textos orais e escritos de diferentes gêneros: discussões em sala de aula sobre identidade profissional docente subsidiadas por leituras de artigos científicos, narrativas de vida, respostas a perguntas etc.

Ambos os estudos embasam-se na perspectiva do Interacionismo sociodiscursivo (BRONCKART, 1999), porém o de Denardi e Oliveira (2014) procurou investigar as (re)construção da identidade do professor de inglês através de textos narrativas de vida e resposta a uma questão sobre a identidade dos participantes, guiando-se por 2 questões de pesquisa: 1) Que marcas/evidências linguísticas podem ser reveladoras de questões identitárias nos textos?; b) O que essas marcas/evidências linguísticas revelam sobre a identidade profissional dos professores-participantes? Para tal, procurou-se identificar os tipos de discurso, as vozes e as figuras de agir predominantes nas narrativas de vida das participantes e na resposta de uma questão sobre suas identidades. Com relação aos tipos de discurso predominam o relato interativo e o discurso interativo, ambos da ordem do narrar. Já com relação às vozes, são predominantes as vozes das próprias professoras e vozes sociais observáveis através das referências que fazem a teóricos que estudaram durante o curso. Por fim, as figuras de agir predominantes identificadas foram evento passado (histórias das participantes) e ocorrência (interação com o outro na trajetória de vida).

Em suma, as marcas linguísticas identificadas nos textos analisados revelam

aspectos da trajetória de vida dos professores-participantes referentes: a) à origem familiar; b) ao percurso escolar-acadêmico; c) ao casamento e filhos; d) ao início da vida profissional como professor; e e) ao desenvolvimento profissional contínuo. Essa trajetória de vida é construída com a interação com outras histórias, pessoas, professores, formadores e teóricos, revelando que o professor é constituído por vários outros em sua caminhada. Os dados também revelam que os professoresparticipantes tiveram que dispender grandes esforços para se tornarem professores 
de inglês na rede pública, e que continuam se esforçando para a manutenção da profissão. Por outro lado, sentem grande responsabilidade sobre sua própria formação, visando ao progresso acadêmico-profissional, consequentemente, (re)construindo sua identidade profissional (p. 577-578).

Passando para o artigo de Denardi e Gil (2015), é importante considerar que apesar do mesmo focar na mesma temática ter sido gerado no mesmo contexto de pesquisa do de Denardi e Oliveira (2014), distingue-se por ser escrito em língua inglesa, e, principalmente, pelo objetivo, questões de pesquisa, material documental e metodologia de análise dos dados. Dessa forma, o artigo objetivou investigar a (re)construção de identidade das professoras participantes através da análise interpretativista de textos orais e escritos produzidos pelas professoras, a saber: discussão de textos teóricos sobre a temática de construção de identidade do professor e sobre ensino-aprendizagem de língua inglesa no contexto brasileiro, suas narrativas de vida, respostas a uma questão sobre suas identidades. A análise dos dados tentou responder a 3 perguntas de pesquisa: 1) quais as características comuns das identidades pessoais e profissionais dos professores participantes?; 2) como os professores participantes se veem como professores de inglês como língua adicional?; e 3) que expectativas eles têm como professores de inglês como língua adicional?

As análises apontaram para os seguintes resultados:

\begin{abstract}
a)as identidades dos professores parecem ser fragmentadas e construídas através de suas trajetórias de vida; b) as professoras se vêem em constantes mudanças e num processo de desenvolvimento profissional contínuo devido às mudanças na relação ao papel do professor de inglês de escola pública e ao status da língua inglesa como língua adicional no mundo contemporâneo; c) as trajetórias de vida dos professores de inglês como língua adicional (...) são essenciais na construção de suas identidades profissionais e acadêmicas (p. 20, tradução dos autores).
\end{abstract}

Ademais, as autoras consideram que a experiência vivenciada no curso através de produções textuais orais (discussões sobre textos teóricos) e escritas (narrativas de vida) em inglês foram oportunidades que as professoras tiveram de refletir sobre suas formas de aprender e ensinar a língua inglesa, bem como desenvolver uma visão crítica sobre seus papeis e identidades como professores de inglês como língua adicional. Com relação à pesquisa, as autoras dizem ser o texto relevante para a área de formação de professores de inglês como língua adicional, uma vez que o mesmo tentou abordar as necessidades, conflitos e expectativas de professores de inglês da região sudoeste do Paraná, interessados em seu desenvolvimento acadêmico e profissional, ao mesmo tempo que procurou denunciar como os professores percebem as necessidades e também as dificuldades que têm para tomada de decisões coletivas a favor da escola pública ao se descobrirem como profissionais capazes de entender as políticas educacionais, a organização do trabalho pedagógico, o contexto social no qual estão inseridos e o papel social de aulas de língua inglesa no Brasil.

Tendo apresentado os 5 trabalhos selecionados para a análise, as próximas subseções procurarão responder as questões de pesquisa deste trabalho.

\title{
Caracterização dos Estudos e o Conceito de Identidade Profissional Docente
}

Esta subseção objetiva responder as 2 questões de pesquisa postas na seção metodologia deste texto, ou seja: a) Como os estudos de pesquisadores paranaenses são caracterizados?; e b) Que conceitos de identidade e conceitos subjacentes emergiram dos dados analisados?

\section{Como os estudos de pesquisadores paranaenses são caracterizados?}


Os estudos de pesquisadores de instituições de ensino superior do Paraná publicados em periódicos da área entre os anos 2006 e 2016 constituem-se de 5 pesquisas qualitativas de cunho interpretativista, cujos objetivos são relacionados e que seguem perspectivas teóricas sociointeracionistas e pós-estruturalistas através de aportes teóricos vygotskinianos, foucaultianos, bronckartinianos e de seus seguidores das áreas de linguística aplicada e de formação de professores de Inglês, bem como se apoiam em pressupostos teóricos fillosóficos e sociológicos advindos dos estudos de Freire (1998, 2005); Hall (1996, 2000, 2005), Bahaba (1994) respectivamente.

Quatro destes são pesquisas de campo e uma é uma de cunho bibliográfico. O texto essencialmente teórico discute a relação existente entre identidade do professor de inglês e sua agentividade, entendendo a identidade de professores como "hibrida" (não pura, resultado da relação língua e subjetividade), e que professores têm capacidade crítica de intervir e transformar realidades.

Com relação às quatro pesquisas de campo, essas têm como objetivo em comum investigar a (re)construção da identidade do professor de inglês, entendendo como essa se constitui e que implicações e influências têm para o professor em seus processos de ensinar e aprender a língua inglesa.

Nas pesquisas empíricas são participantes professoras em formação e em formação continuada. A ausência de participantes do sexo masculino nos trabalhos investigados, não causa estranheza uma vez que os profissionais e futuros profissionais de educação básica são em sua grande maioria femininos no Brasil. Importante também ressaltar o papel dos pesquisadores nos trabalhos de campo. No estudo realizado por Da Silva et al (2007), os pesquisadores são internos, isto é são ao mesmo tempo pesquisadores e participantes, o que permite que ao refletirem sobre suas práticas pedagógicas e trajetórias profissionais, reconstruam suas identidades profissionais. Já nos estudos de Gamero e Cristovão (2013), Denardi e Oliveira (2014) e Denardi e Gil (2015), os pesquisadores são externos à pesquisa se consideramos que não analisam seu próprio fazer enquanto pesquisadores, porém por outro lado também estão envolvidos diretamente na pesquisa pois são professores dos participantes sejam em curso de graduação em licenciatura em Letras-Inglês ou em cursos de extensão de formação continuada de professores de inglês.

Ainda, com relação aos aspectos metodológicos de coleta e análise de dados das pesquisas empíricas observou-se a utilização de diferentes instrumentos de documentação nomeadamente: textos orais produzidos pelos participantes nas interações em sala de aulas, relatos de aulas observadas, narrativas de vida, opiniões registradas por escrito sobre si mesmo e diários reflexivos sobre práticas pedagógicas das participantes.

Já com relação aos instrumentos usados para a análise dos dados, as pesquisas empíricas se valeram de análises descritivas e interpretativas de diferentes naturezas, ou seja: tanto de uso de categorias de análise pré-selecionadas como de categorias de análise que emergiram dos dados.

\section{Que conceitos de identidade e conceitos subjacentes emergiram dos estudos investigados?}

Sintetizando os conceitos de identidade presentes nos estudos investigados, pode-se dizer que os conceitos de identidade encontrados são pertinentes às abordagens teóricas que os embasam, isto é sociointeracionistas e pós-estruturalistas e, dessa forma, concebe-se a identidade profissional docente como "hibrida", uma vez que a língua e a cultura que estuda e ensina se mesclam com a própria língua e cultura do sujeito professor. É também fragmentada e em constante transformação devido aos papeis que o professor desempenha em diferentes contextos de interação social e às mudanças do mundo contemporâneo. A identidade docente, ainda é concebida como um processo contínuo de desenvolvimento de si, 
a partir de interações com o outro, é portanto dialógica, plural e sócio-historicamente construída.

A seguir, algumas considerações sobre o trabalho de sistematização de estudos sobre identidade profissional do professor de inglês sob a ótica de pesquisadores atuantes no contexto paranaense e publicados no período de 2006 a 2016 serão apresentadas.

\section{Algumas considerações}

Procurou-se neste trabalho apresentar uma sistematização de estudos sobre a identidade do professor de inglês sob a ótica de pesquisadores atuantes em programas de pósgraduação de universidades públicas do Estado do Paraná, publicados em periódicos da área de Linguística Aplicada entre os anos de 2006-2016. 5 trabalhos foram identificados e analisados. A análise focou nos parâmetros de produção dos artigos, perspectiva teórica, metodologia, resultados e no conceito de identidade adotado e emergente nos trabalhos.

Com relação ao conceito de identidade profissional docente, foco principal das pesquisas, tal sistematização possibilitou observar que as premissas apontadas pelos teóricos se confirmam através dos dados analisados, evidenciando que a identidade profissional docente, neste caso do professor de inglês, é fragmentada, multifacetada, mutável, construída ao longo da história de vida do professor e influenciada pelo próprio objeto de trabalho, a língua inglesa e seu papel na sociedade contemporânea. Portanto, constitui-se sóciohistoricamente nas diferentes relações e contextos sociais dos quais o professor participa, como já apontado na seção anterior.

Reitera-se, aqui, a importância do levantamento de estudos aqui apresentados pelos pontos de congruência que apresentam, mas, principalmente, por evidenciar certas lacunas na formação do professor de inglês, como por exemplo a questão apontada no estudo de Gamero e Cristovão (2013) que se refere à dificuldade dos professores em relacionar teoria-prática em suas representações sobre ensinar e aprender no estágio de docência. Neste sentido, observase a importância de provocar reflexões sobre a temática desde os primeiros estágios dos cursos de formação, uma vez que formar um professor consciente do que é e do que é capaz refletirá no seu trabalho futuro revertendo em ganhos na qualidade de ensino e de aprendizagem das futuras gerações. Por outro lado, o estudo de Denardi e Gil (2015) aponta que o professor de inglês ao mesmo tempo que percebe as necessidades de sua profissão têm dificuldades para engajar-se em projetos de luta em prol da escola pública e de políticas educacionais e linguísticas.

Sugere-se, dessa forma, que os cursos de licenciatura em letras inglês e curso de formação continuada de professores de língua inglesa enfatizem a formação específica para a docência e oportunizem maior espaço para discussões e práticas sobre as ações de ensinar, mediar e apoiar a aprendizagem de ser professor.

\section{Referências}

CELANI, M.A.A.; MAGALHÃES, M.C.C. Representações de professores de inglês como língua estrangeira sobre suas identidades profissionais: uma proposta de reconstrução. In: MOITA LOPES, L. P. (Org.). Discurso de identidades: discurso como espaço de construção de gênero, sexualidade, raça, idade e profissão na escola e na família. Campinas: Mercado de Letras, 2003, p. 319-337.

DA SILVA; GREGGIO, S. ; LUCENA, C. ; DENARDI, D. A.C. ; G.G. Narratives: unveiling teachers' identities. Signum. Estudos de Linguagem, v. 10, p. 199-222, 2007. 
DENARDI, D. A. C. ; OLIVEIRA, S. M. . Uma análise linguístico-discursiva das marcas identitárias do professor de língua inglesa. Eutomia (Recife), v. 1, p. 562-580, 2014.

DENARDI, D. A. C. ; GIL, G. . How do i see myself? What do I want to become? A study on English as an additional language teachers' identity reconstruction. Trabalhos em Linguística Aplicada, v. 54, p. 137-160, 2015.

ELBAZ, F. The teacher's "practical knowledge": report of a case study. Curriculum Inquiry, 1981, 11/1, p. 43-71.

GAMERO, R. ; CRISTOVÃO, V. L. L. . A Construção de Identidade Profissional no Estágio de Regência de Inglês. Revista Eletrônica do Pro-Docência, 2013, v. 1, p. 80-92.

GIMENEZ, T. Reflective teaching and teacher education: contributions from teacher training. Linguagem \& Ensino, 1999, 2/2, 129-143.

GIMENEZ, T. Trajetórias na formação de professores de línguas. Londrina: EDUEL, 2002.

JOHNSON, K. ; FREEMAN, D. Teacher learning in second language teacher education: a socially-situated perspective. Revista Brasileira de Lingüística Aplicada, 2001, 1/1, p.5369.

JORDÃO, C. M.. A posição de professor de inglês no Brasil: hibridismo, identidade e agência. Letras \& Letras (Online), 2010,v. 26, p. 427-442.

NÓVOA, A. Formação de professores e trabalho pedagógico. Lisboa: EDUCA, 2002.

RAJAGOPALAN, K. Por uma linguíística crítica: linguagem, identidade e a questão ética. São Paulo: Editora Parábola, 2003.

RICHARDS, J. C. The scope of second language teacher education. In J. C. Richards (Org.). Beyond Training. Cambridge: Cambridge University Press. 1998, p. 1- 48.

SHULMAN, L. S. Knowledge and Teaching: foundations of the new reform. Harvard Educational Review, 1987, 57/1, p. 1-22.

TELLES, J. A. Metaphors as coalescences of teachers' beliefs of language, their students and language teaching. Revista do Instituto de Letras, 1997, 16, 1/2, p. 86-115.

VIGOTSKY, L.S. Mind in society: the development of higher psychological processes. Cambridge, MA: Cambridge University Press, 1978.

ZEICHNER, K. M. Educating reflective teachers for learner-centered education: possibilities and contradictions. In: T. Gimenez (Org.). Ensinando e aprendendo inglês na universidade: formação de professores em tempos de mudança. Londrina: ABRAPUI, 2003, p. 3-19. 